\title{
Development and Improvement of the Regulation Sieve
}

\section{System Harvester}

\author{
Evandro Bertoldi ${ }^{1}$, Gil Eduardo Guimarães ${ }^{1}$, Luiz Carlos da Silva Duarte ${ }^{1}$, Patricia Carolina Pedrali ${ }^{1}$, Claudio \\ Fernando Rios ${ }^{2}$, Nara Liege Barbieri ${ }^{3}$ and Everton Bertoldi ${ }^{4}$ \\ 1. Mechanical Engineering Department, UNIJUÍ-Regional University of Norhtwest of Rio Grande do Sul State, Panambi 98280-000, \\ Brazil \\ 2. Mechanical Engineering Department, FTEC-School of Technology, Caxias do Sul 95012-669, Brazil \\ 3. Agronomy Departament, UPF-Passo Fundo University, Passo Fundo 99001-970, Brazil \\ 4. Mechanical and Production Engineering Department, UPF-Passo Fundo University, Carazinho 99500-000, Brazil
}

Received: May 02, 2014 / Accepted: May 23, 2014 / Published: August 25, 2014.

\begin{abstract}
Due to high competition of the agriculture machines sector, the auto parts suppliers are investing in research to promote the development and reduce the costs of the products, passing these results to their clients who are the automakers. It was identified the need to redesign the regulation sieve system harvester, which is a compound assembly in the harvester's grain cleaning system, with the objective to reduce the costs and improve the ergonomic aspect, keeping the same efficiency from the original project. The improvement was developed by studying the original design and identifying possible project fails, such as components and manufacturing process which could be eliminated. For this, it was needed to do a research about rules and project considerations that must be applied in the products development and ergonomic too, specifically about geometric forms and anthropometric measures. From the redesign of this system, it is verified that it is possible by a study to identify possible improvements, and to develop a new system by a simple project, improving the ergonomic, reducing the cost and keeping the same efficacy from the original project.
\end{abstract}

Key words: Lower costs, ergonomic, redesign, regulation system, harvester.

\section{Introduction}

With the intention to reduce the products cost, the need to analyze the possibility of redesigning some projects was identified. The sieve is a compound assembly to the harvester's grain cleaning system.

The sieves are compounded by many parts made from different materials and manufacturing processes. Among them, it has the possibility to redesign the regulation of the lamella system, in an effort to reduce the cost and improve the ergonomic aspects, keeping the same efficiency as the original project.

Once, the need for improvement was identified in the regulation sieve system, an analysis was made in

Corresponding author: Gil Guimarães, Ph.D., mechanic engineer, research field: lean manufacturing. E-mail: gil.guimaraes@unijui.edu.br. the original project to identify possible project fails with the following goals: reduce the costs; improve the ergonomic aspects; keep the durability from the original design; make it easy handling and operation; make it easy to assemble and manufacture; lessen the possible number of compounds, lessen the possible number of manufacturing and assembling process.

This analysis consider some criteria, recommendations and rules such as project for ergonomic, project for economy, material selection, project for settings, project for manufacturing, project for assemble and project for reliability. This analysis allowed identifying many improvement opportunities that can be made according to the available resources.

From this system redesign with a methodology and project rules, it was possible to develop a new system 
from a simple conception, improve the ergonomic, reduce the cost and keep the same efficacy from the original project.

The developing of this paper is organized in three sections. Section 2, material and methods, describes the most relevant project considerations used in the phases of regulating system, and the phase of basis knowledge or analysis of the original project; Section 3, results and discussion, presents the new regulating system made from the methodology and redesign, comparing to the current regulating system; At last, Section 4 presents the conclusion and final considerations.

\section{Materials and Methods}

The redesign project of the regulating sieve system is based on Dufour and Valdiero [1, 2], which can be divided into the following stages: knowledge base, analysis of similar, analysis of needs, design concept, previous concept, detailed redesign, prototype construction, tests and modifications.

Now, it will present the most relevant project considerations which are used in the regulating redesign stages, the base knowledge or analysis from the original project and the new regulating system developed from the redesign methodology named previously.

\subsection{Project Considerations}

Project is a guided activity to care human needs, mainly the ones that can be satisfied by technology factors [3].

The redesign process of industrial products is the activity that inserts changes in the original project, satisfying and preserving its functional requirements in an attempt to create possible alternatives to present the better care that human needed [4].

\subsubsection{Design for Ergonomic}

The most relevant project considerations referring to ergonomic is based on Iida, Back and Grandjean [3, 5, 6], however, to get a better understanding, it will be described some criteria used, according to the previously named authors.

The ergonomic is the study of adaptation of the work to men. The practical goals of ergonomic are safety, satisfaction, and workers' wellness obtaining the efficacy as a result [5].

The operation is the way whereby, it is possible for men to transmit the commands movements to the machine. There are two basic types of handling, as illustrated in Fig. 1: gentle and rude handling [5].

The catch movement with the fingertips, having thumb in opposition to the others, allows transmit a maximum force of $10 \mathrm{~kg}$. For rude handling, with all the fingers closing around the object, the strength can reach $40 \mathrm{~kg}$. The tension concentration in the hand can be minimized, to improve the catch design and to increase its diameter and eliminate alive-corners [5].

The human body efficacy depends on many factors, and presents so many variations that it is hard to speak in average capacity. Even though, researchers raised valuable data for the designer. Fig. 2 shows many performance cases with the respective strength [3].

The anthropometric method is about human body physical measure [5]. The hand measures are very important, because the main purpose of the hand measures is to set the controls in machines. Table 1 and Fig. 3 present the hand measures [6].

The sizes of the numbers and words have influences on its readability. The sizes of the numbers depend on the reading distance. It is recommended that there are more specific dimensions according to Table 2 for different reading distances [5].

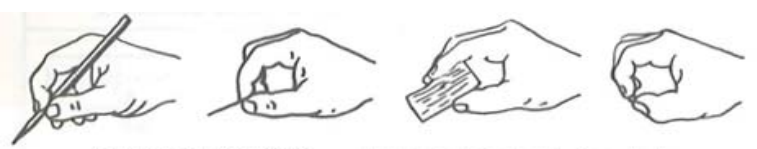

(A) MANEJO FINO - Pega com a ponta dos dedos

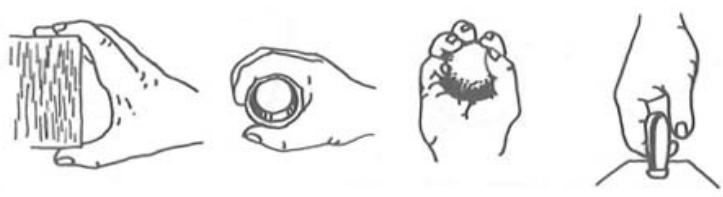

(B) MANEJO GROSSEIRO - Pega com a palma da mão

Fig. 1 Basic handling types. 


\subsubsection{Design for Economy}

The use of standard size or stock is a primary principle of cost reduction. The sales of materials and manufactured parts usually cost less than unusual components size [7].

Among the effects of the project specifications on costs, those related to the tolerances are of greatest significance. The project tolerances influence the final product productivity in many ways [7].

There are many ways to compare the costs of two projects as the parts' numbers. Other estimative costs can be used as area, volume, horsepower, torque, capacity and others [7].

\subsubsection{Material Selection and Applying}

The selection and application of the material in the project is about the relation between material properties and functions in the manufacturing process and the supply condition and costs. For a proper material selection, it is recommended many aspects analysis. Some relevant aspects for the regulating system redesign are manufacturing process, material supply, material costs and mechanical properties [3].

The most common test of the material for the main mechanical properties is the traction, in which tension versus deformation diagrams are obtained [3]. These tests allow the determination of values such as the drain tension $(\sigma \varepsilon)$, resistance $(R m)$ and elongation (\% $A l)$ [8]. For the material selection of the regulating system, the mechanical property which will be examined is $\sigma \varepsilon$, due to perform numerical simulation, using the linear to obtain the tension and deformation map analysis, in which the results will be compared with the material $\sigma \varepsilon$. The drain tension or yield point that shown in Fig. 4 is the charge which delimits the elastic range of the material, and the load limits on the deformations are still reversible. For most metals, the elastic behavior is linear.

\subsubsection{Design for Configuration}

After determinate main key parameters, it starts the determination of general layout, preliminary component forms and possible interferences. The dimension, layout and definitive geometric forms are obtained through some basic principles. The project criteria for configurations used in this development is based on Back [9].

\subsubsection{Design for Manufacturing}

For manufacturing, the design must be set up in a way that will compose the components together, in order to simplify the manufacturing and obtain the necessary precision with lower costs. From the prospective of geometry, material and number of parts can be produced, it is selected, and the manufacturing

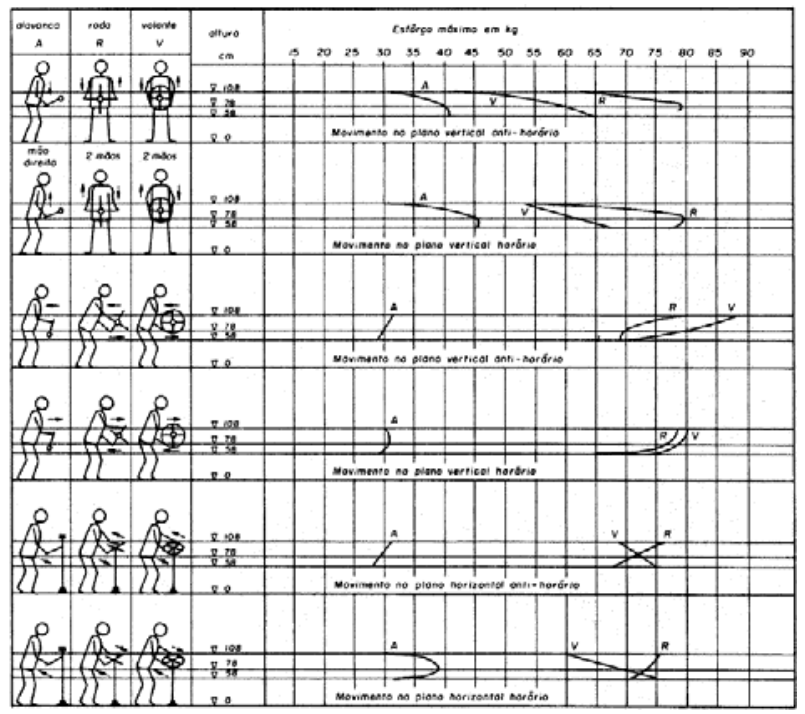

Fig. 2 Efforts and commands various data.

Table 1 Anthropometrics' hand measures in centimeters.

\begin{tabular}{llllll}
\hline \multirow{2}{*}{$\begin{array}{l}\text { Measure } \\
\text { number }\end{array}$} & Antropometric measure & \multicolumn{2}{c}{ Men } & & \multicolumn{2}{c}{ Women } \\
\cline { 3 - 4 } \cline { 5 - 6 } & Average & LC 90\% & Average & LC 90\% \\
\hline 1 & Hand perimenter & 21.1 & $19.3-23.0$ & 18.7 & $17.5-20.1$ \\
3 & Hand lenght & 10.6 & $9.8-11.1$ & - & - \\
4 & Wist perimeter & 17.1 & $15.5-18.8$ & 16.1 & $14.3-17.9$ \\
\hline
\end{tabular}



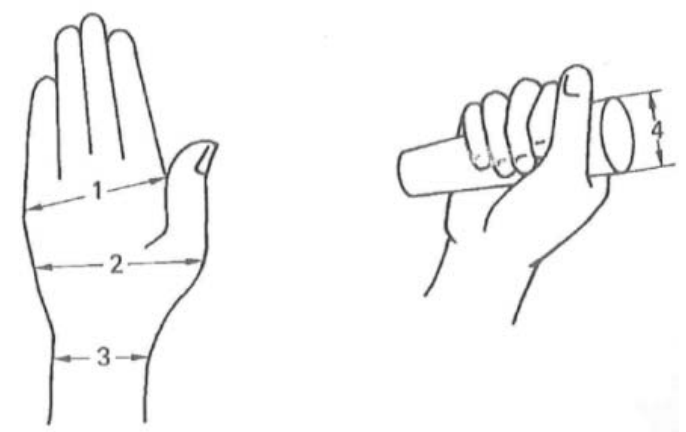

Fig. 3 Measure indication from Table 1.

Table 2 Height word dimension for different distances.

\begin{tabular}{ll}
\hline Reading distance $(\mathrm{mm})$ & Word size $(\mathrm{mm})$ \\
\hline $0-500$ & 2.5 \\
$500-900$ & 4.5 \\
\hline
\end{tabular}

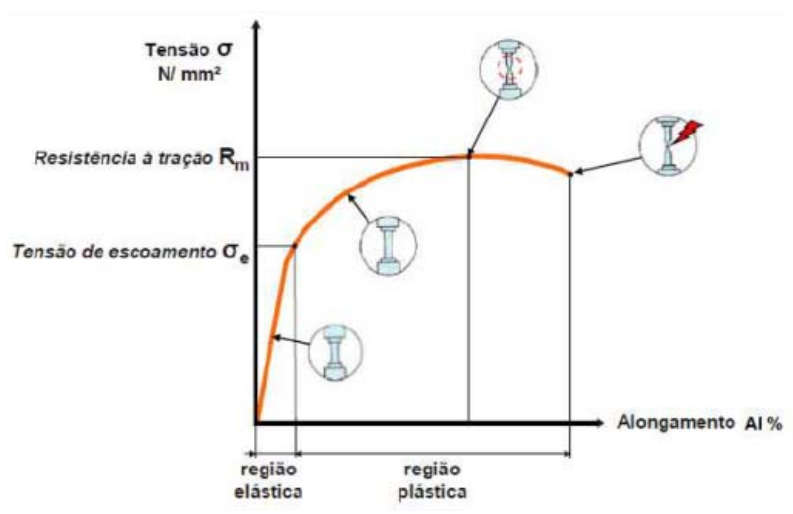

Fig. 4 Example of engineer curve in a traction test.

process can better fit the specifications. The manufactory design is usually treated together with the material selection and the problem of assembling the components as one product. Furthermore, some design recommendation for the manufacturing design can ease manufacturing, simplify the design and reduce de number of parts, in order to normalize parts and material used, to optimize design within capacity limits of manufacturing processes [9]. The materials are formed by removal and deformation or combination of these forms in the main manufacturing processes of the stamping and machining [3].

\subsubsection{Design for Assembly}

The assembly involves the combination of parts or assemblies to obtain a final product. The manufacturing and assembling must be examined together, because the design recommendations to make these activities easier can be conflicting. To facilitate the assembly, it used the principles described by Back [9].

\subsubsection{Design for Reliability}

The reliability is defined as a system probability or product to perform its function in a satisfactory way for a certain period of time, when handled under specific handling conditions. To get the reliable optimization of a product, it is recommended the design principles presented by Back [9].

\subsection{Original Project Analysis}

The information of this phase of the redesign project is contained in the product life cycle. This consists in the following steps: project and production, distribution, use and operation, and disposal [2].

The information needed to start the redesign were obtained from the study of project phase and production of the product life cycle, it can obtain from the project analysis, and can draw from the current regulating system, identifying manufacturing characteristics, assembly, dimensions, ergonomic, requests, materials, process and costs.

In addition to the information which obtain from the redesign phase and production of product life cycle, the internal customers (production) helped to identify factors that contributed to reduce the manufacturing cost. The internal customers also passed as external clients (consumer and direct user) in order to identify fails in the current regulating system.

2.2.1 Analysis of the Current System Assembly Regulating

The assembly design of the current regulation system is detailed from the figures below. It starts with the assembly of the regulation level set, after that, it assemble in the sieve.

Fig. 5 shows the exploded view of the regulation lever set with the indication of the components, which has the following assembly:

- Assemble the adjusting plate (2) in the welding lever (1), observing the correct position of the holes 
assembling, through an $\varnothing 5 \times 10$ rivet (3). The riveting procedure is made with a steel hammer and, if the rivet (3) is too heavy in movement, we must pass lubricating oil on it;

- Assemble the welding riddle (5) to two A6 × 12.5 $\times 1.6$ flat washers (4), used as a spacer, in welding lever set (1), through a M6 $\times 18$ hexagonal screw (6), a A6 $\times 12.5 \times 1.6$ flat washer 7 , and a M6 self-lock nut (8). The screw tightening must allow the riddle to rotate freely;

- Finally, assemble the extension spring (9) in the welding lever set (1)and in the wielding riddle set (5).

After the adjusting lath assembly, the next step is the assembly of adjusting system in the sieve set. Next, as shown in Figs. 6 and 7, it described the assembly procedure for the current regulating system:

- To assemble the solder adjustment guide set (1) on the lamellae axes;

- To assemble the adjusting guide protection (2) on the welding adjusting guide (1), and fix it by seven 3.9 $\times 13$ DIN 7982 flathead screws (3) with slit;

- To assemble the adjusting lath set (4) on the sieve, and fixing it by two M6 self-locking nuts (6) and two A6 $\times 12.5 \times 1.6$ flat washers (5). The nuts tightening must allow the adjusting lever set turn freely.

2.2.2 Analysis of Solder Current Regulating System

The welded assemblies that are part of the current regulation system design are detailed below.

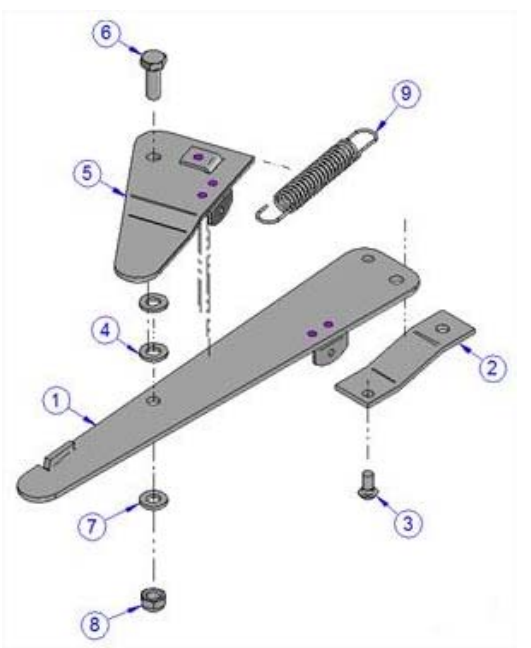

Fig. 5 Exploded view of the current adjusting lath.

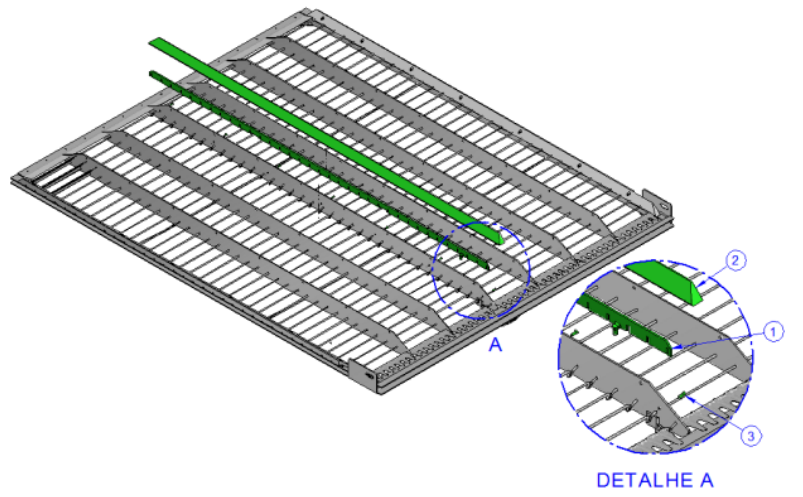

Fig. 6 Top part of the sieve with assembling detail of the current regulating system.

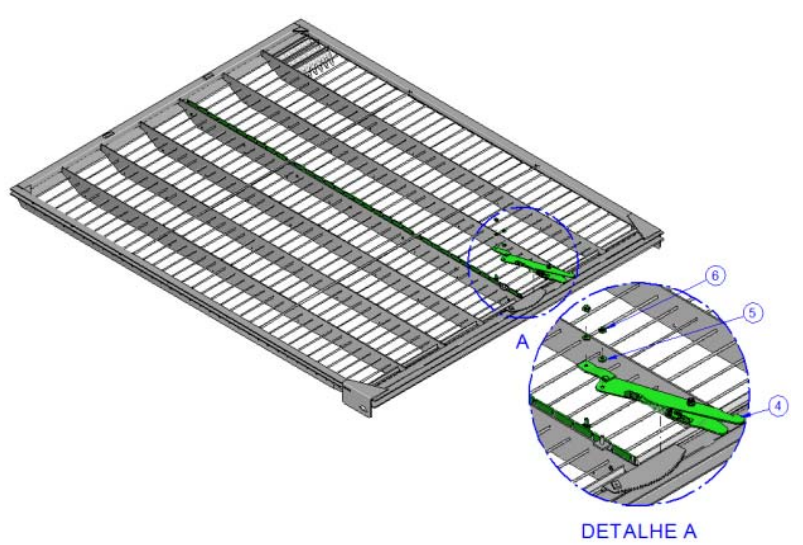

Fig. 7 Lower part of the sieve with assembling detail in the current regulating system.

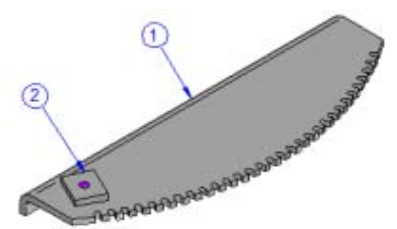

Fig. 8 Isometric view of the rack welding set.

Fig. 8, the welding rack set has the following components and welding procedure:

- Welding-points is the lock (2) in the rack (1) with a device.

The adjustment welding guide set shown in Fig. 9 is welded as the following procedure:

- Electric arc-weld with shield gas (MAG) is a hexagonal screw M6 $\times 12$ (2)on the tab adjustment (1) with a device.

The lever solder regulation set has the following welding procedure, as shown in Fig. 10:

- Welding-point is a coupler spring (2) in the regulation lever (1) with a device. 


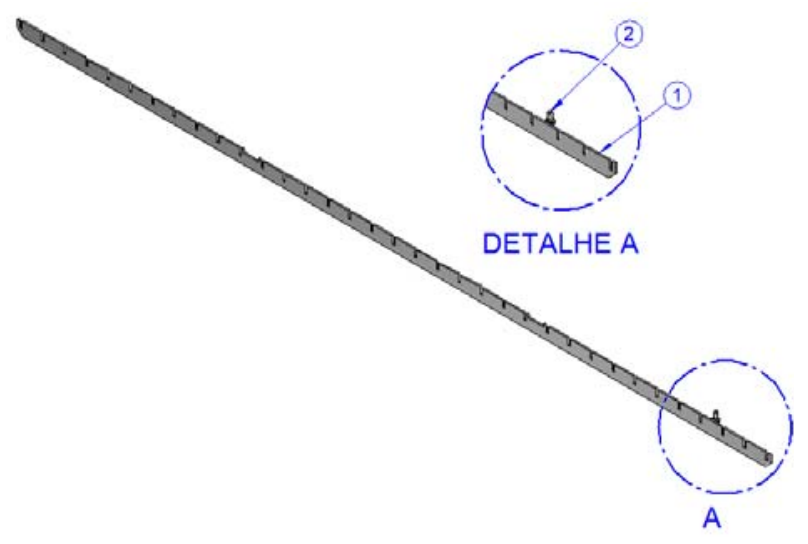

Fig. 9 Isometric view of the solder guide adjustment set.

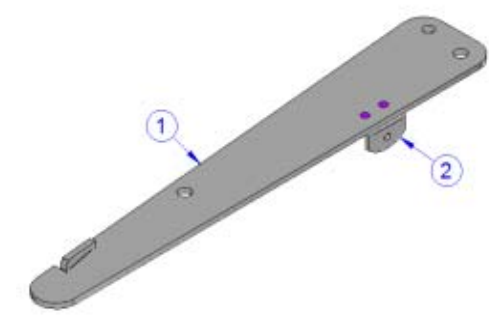

Fig. 10 Isometric view of the lever solders set.

Fig. 11 shows the solder locking piece lever set which has the below welding procedure:

- Welding-point a coupler spring (3) with device and a lock (2)with no device in the locking piece (1).

Fig. 12 shows the system components of the regulating system which are welded on the board solder set. The welding procedure is presented below:

- Welding with MAG a regulating coupler (2) with device on the board solder set;

- Welding with MAG a hexagonal screw M6 × 12

(3) with no device in the regulating coupler (2);

- Welding with MAG a solder rack set (1) with a device in the solder board.

2.2.3 Analysis of Manufacturing Current Regulating System

The manufacturing design of the components which are part of the regulating system is detailed described for each component.

Fig. 13 shows the regulating coupler which is a welded component in the solder board set. The components have the following manufacturing process and material:

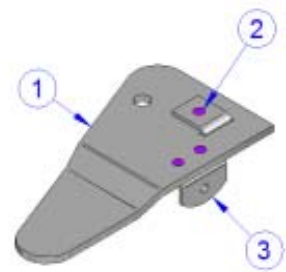

Fig. 11 Isometric view of solder locking piece set.

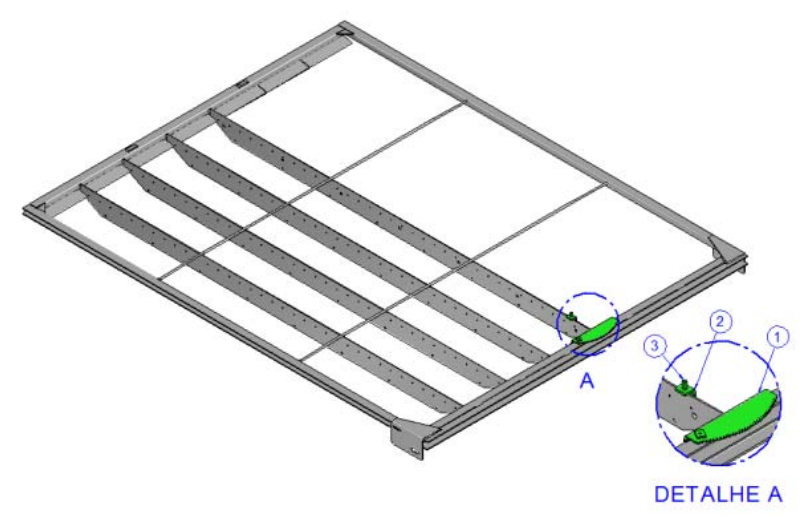

Fig. 12 Lower part of solder board set with welding detail of the current system.

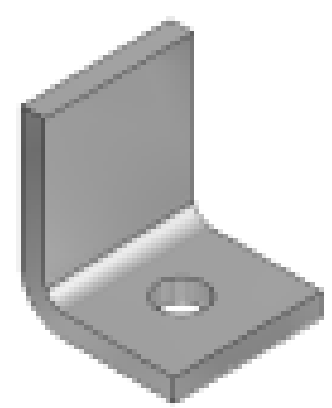

Fig. 13 Isometric view of the regulating coupler.

- Material Thickness 3.0 mm SAE 1008;

- Cut the plate into strips;

- Stamping and bend with a tool.

The regulating guide, shown in Fig. 14, is the welded component in the regulating solder guide, which has the following material and manufacturing material:

- Material thickness 3.0 mm SAE 1008;

- Cut the plate into strips;

- Stamping the cutouts with a tool;

- Stamping the chamfers with a tool;

- Straight and check with a ruler the straightness;

- Cut in half to have two parts with device;

- Straight and check the straightness visually. 


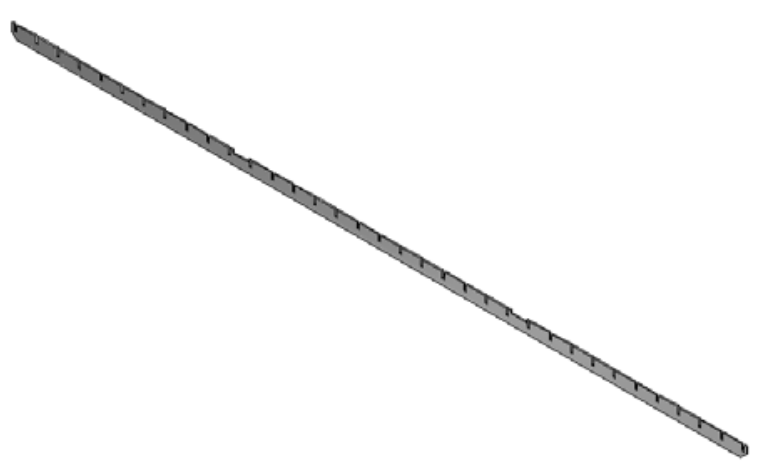

Fig. 14 Isometric view of the regulating guide.

The material and manufacturing material for the regulating lever shown in Fig. 15 is below:

- Material thickness 2.65 mm SAE 1,008;

- Cut the plate into strips with tool;

- Stamping blank (flattened) with tool;

- Stamping and twitch with tool.

The spring couplers in Fig. 16 are usual components welded in a regulating solder lever set and in the locking piece solder set. This component has the material and manufacturing procedure below:

- Material thickness 1.50 mm NBR 5915 EM;

- Cut the plate into strips and bend two parts by coup with tool.

Fig. 17 shows the locking piece, which has the material and procedure below:

- Material thickness 2.65 mm SAE 1008;

- Cut the plate into strips;

- Cut the blank in laser cutting machine as program;

- Bending with tool.

The locking piece lock, shown in Fig. 18, has material and manufacturing procedure below:

- Material thickness 1.50 mm NBR 5,915 EM;

- Cut the plate into strips;

- Stamping and bending with tool.

The regulating plate, shown in Fig. 19, has the material and manufacturing procedures:

- Material thickness 2.65 mm SAE 1008;

- Cut the plate into strips;

- Stamping holes with tool;

- Bending with tool.

As in Fig. 20, the rack has the material and manufacturing procedure below:
- Material thickness 2.65 mm SAE 1008;

- Cut the plate into strips;

- Stamping teeth and width with tool;

- Bending with tool.

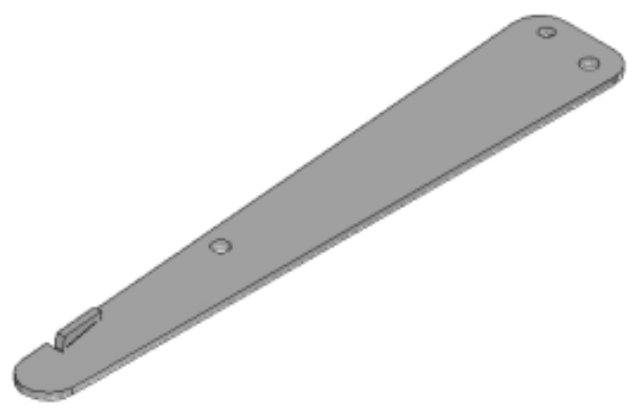

Fig. 15 Isometric view of the regulating lever.

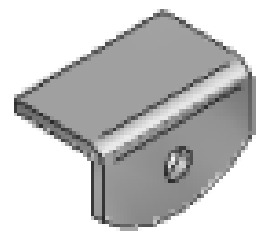

Fig. 16 Isometric view of the spring coupler.

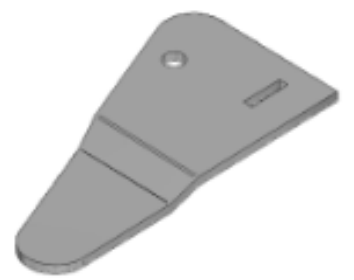

Fig. 17 Isometric view of the locking piece.

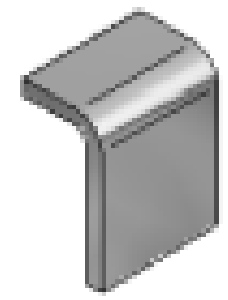

Fig. 18 Isometric view of the locking piece lock.

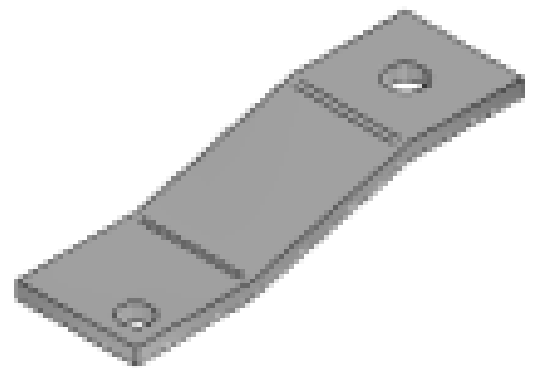

Fig. 19 Isometric view of regulating plate. 


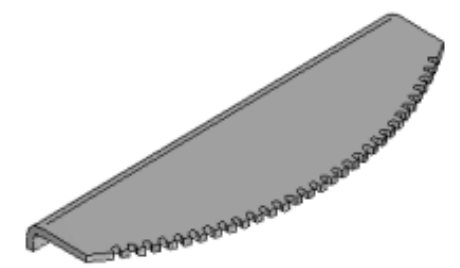

Fig. 20 Isometric view of the rack.

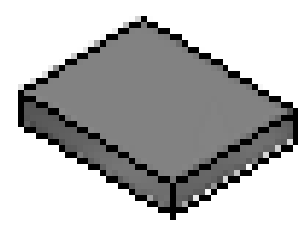

Fig. 21 Isometric view of the rack lock.

Finally, Fig. 21 shows the rack lock which has the material and manufacturing procedure named below:

- Material thickness 2.65 mm SAE 1008;

- Cut the plate into strips;

- Mangling to straighten;

- Distort, straighten and check with a ruler the straightness;

- Cut pieces.

2.2.4 Analysis if the Current Ergonomic Regulating System

About technical quality, the current regulating system performs the action of regulating the sieve lamella opening in a satisfactory way.

From the ergonomic point of view, the handling is harmed because of the regulating lever geometry, which has alive-corners, to the catch diameter and the lever width. Figs. 22 and 23 show that it is possible to visualize that the current regulating lever does not have a favorable geometric form, it has 2.65 mm of thickness, a diameter catch of $20 \mathrm{~mm}$ after pressed the solder riddle to unlock the lever, and the lever width to handle with the hand of $80 \mathrm{~mm}$. These dimensions are very low according to Grandjean [6], who specifies that the average catch perimeter is $13.4 \mathrm{~cm}$, which is about a catch diameter of $4.26 \mathrm{~cm}$, and hand width of $10.0 \mathrm{~cm}$, this way, the tension concentration in the hand do not allowing the proper handle, it may cause injuries and pain to the user. Another analyzed ergonomic aspect was the clear information supply, which allows the user to regulate the desired sieve lamella opening. It is necessary to count the number of teeth in the solder rack set, because there are no indications engraved to make the regulating reading easier, as number or words.

The current system regulating project has no concern about esthetical quality, such as geometric forms, color and textures in order to please visually.

In Fig. 24, we can analyze the way as the movements are sent to regulate the lamella opening trough regulating lever system. On the current regulating lever catch, the fingers have the function to fasten, while the movements are made by the fist and arm. This way, according to Iida [5], is defined the rude handling, as named by the author before, the strength can reach 40 $\mathrm{kg}$. The maximum value of strength applied in this situation validated by Back [3], once the situation

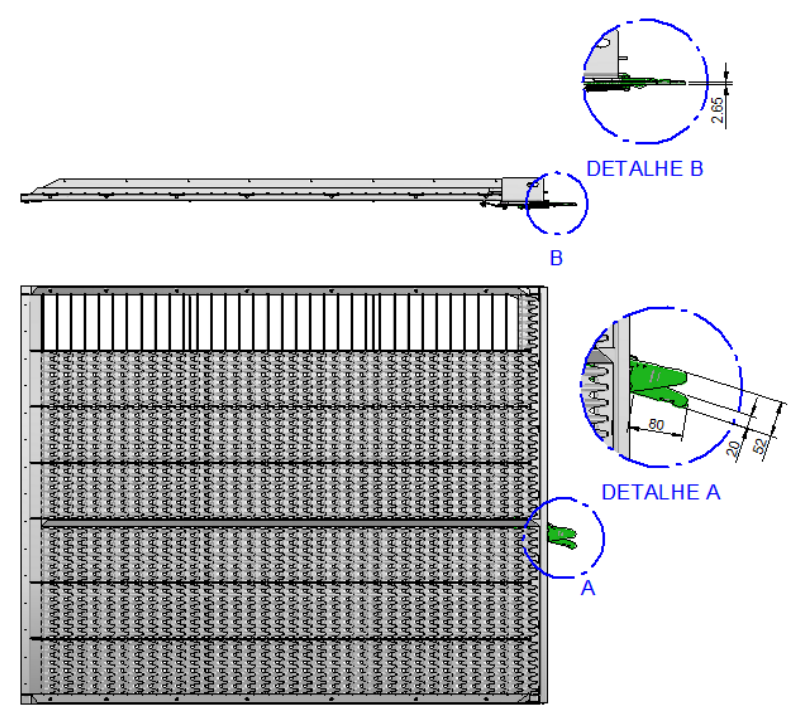

Fig. 22 Front and top view of the sieve with regulating system details.

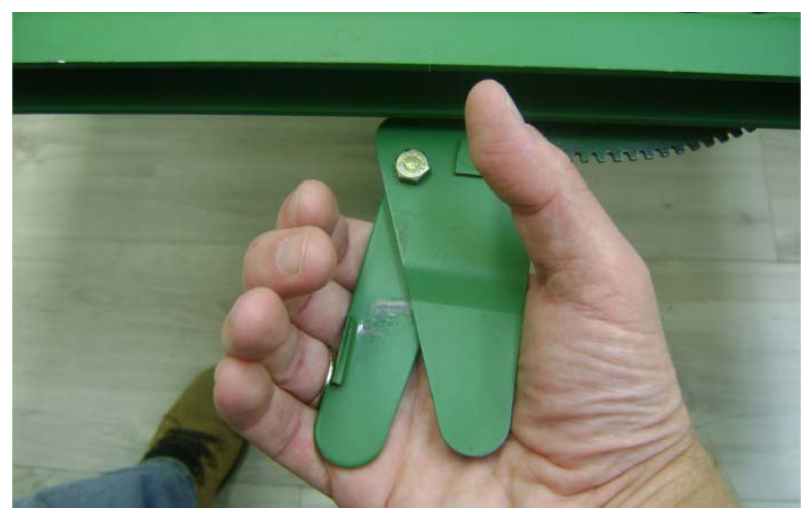

Fig. 23 Handling regulating lever detail. 


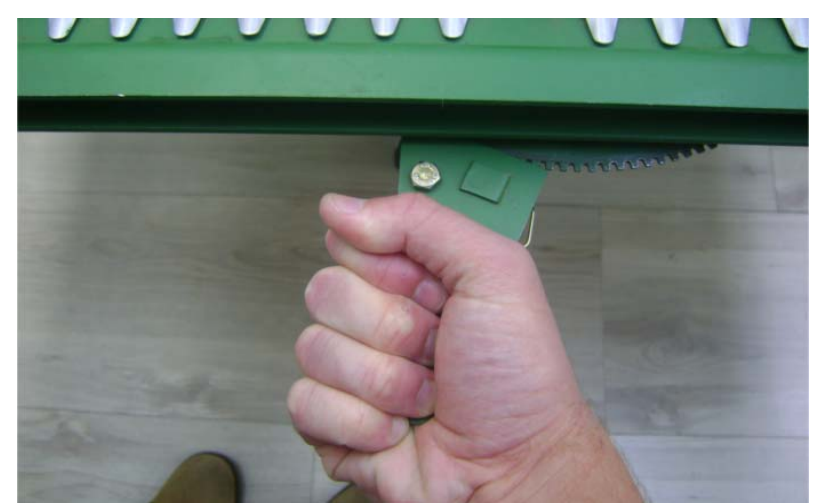

Fig. 24 Regulating catch and handling detail.

is most similar to the regulating lever, that is the lever A, move in the horizontal plan counterclockwise and clockwise, shown in Fig. 2, indicates that the maximum strength is at about $40 \mathrm{~kg}$.

2.2.5 Analysis Requests and Number Simulation of the Current Regulating System

To analyze the structural linear static charge from the current regulating system, it was used a Siemens software, named FEMAP (finite element modeling and postprocessing). In the FEMAP simulation, relevant data must be informed, as piece geometry, charges will be submitted to piece fixation points, Poisson coefficient and elastic modulus.

After an analysis of the regulating current system components, we can check suffer requests during working process, it was observed that the component which suffers more requests is the regulating lever, which has the function to move the regulating guide into longitudinal sieve direction when applied a charge in its extremity.

The charge $\mathrm{F}$, the regulating lever is submitted to regulate, the lamella opening and the fixation points which can simulate finite elements is represented in Fig. 25.

To measure the applied charge in the regulating lever, it was used as a digital libra, and metered according to the calibration certificate.

During the movement of the regulating lever trough the Libra, there were some oscillations in the applied charge value, reaching the maximum value of $9.2 \mathrm{~kg}$ before the regulation reaches the end and lock.

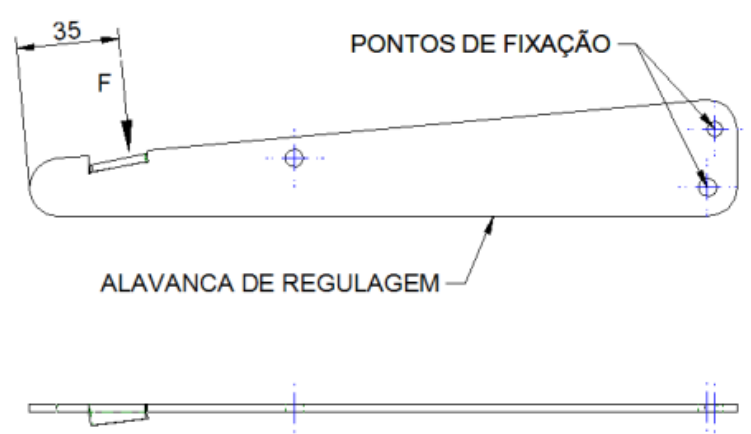

Fig. 25 Charge representation and fixation points to simulate the current regulating lever.

For the simulation, it was adopted a safe coefficient value of 2.17, from the obtained value in the measure, in which the value is $9.2 \mathrm{~kg}$, and in the simulation was considered $20 \mathrm{~kg}$. Even the maximum charge applied by a person in this situation can reach $40 \mathrm{~kg}$, because the charge is necessary to move the regulating lever as only $9.2 \mathrm{~kg}$. It was preferred to use a charge of $20 \mathrm{~kg}$ in the simulation, to use the results as parameters to define a new regulating system and avoid the oversizing.

The simulation finite elements result of the current regulating lever is present next. According to Fig. 26, the maximum tension obtained in the simulation to the loading, as in Fig. 25, is $60 \mathrm{MPa}$. And for deformation, Fig. 27 presents a maximum deformation of $0.5 \mathrm{~mm}$.

Knowing for the current regulation lever is used the material SAE 1008 of thickness $2.65 \mathrm{~mm}$, it was consulted the traction trails information in trail bodies. We can obtain the average tension outflow $(\sigma \varepsilon)$ of 294 MPa.

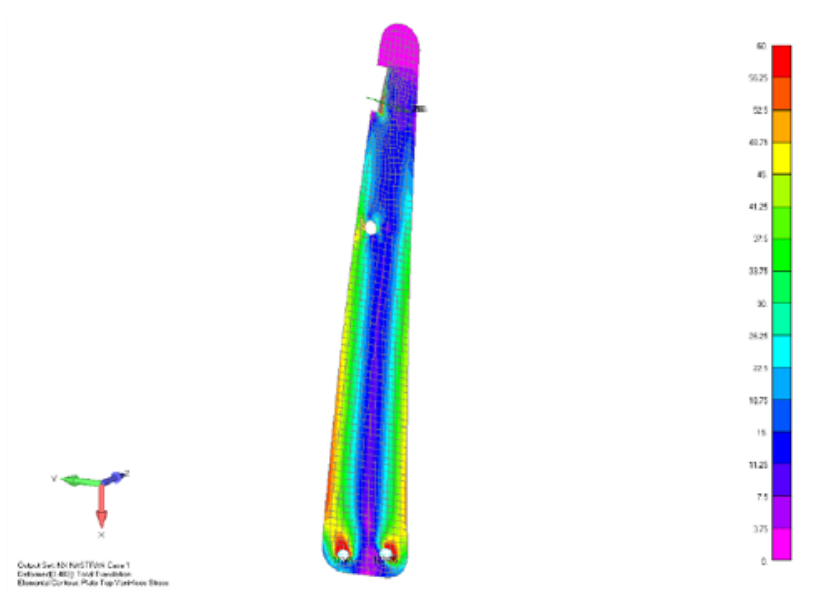

Fig. 26 Tension map for the regulating lever. 


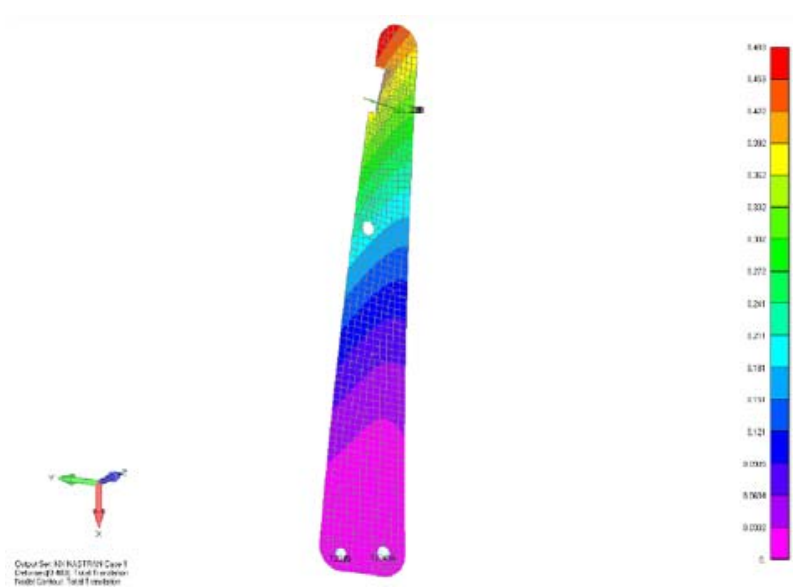

Fig. 27 Deformation map for the current regulating lever.

Based on maximum tension results discovered in the simulation and compared to the tension outflow $(\sigma \varepsilon)$ result discovered in the traction trail, it can be affirmed that the current regulating lever is safely dimensioned.

\section{Results and Discussion}

\subsection{New Regulating System}

It was developed the new regulating system from the redesign methodology mentioned in 2 . The conception chosen trough this methodology in Fig. 28 is described now:

The potency of the new regulating system is produced by human force with manual actuation form a lever (1) which from the rotation movement around the clamping axis, and transmit linear movement into longitudinal direction of the sieve trough the same lever (1), which is fixed in the regulating guide (2), trough the flat washer and locker nut. From this linear movement, the regulating guide (2) moves in longitudinal direction of the sieve making the lamella axis turn around its own axis. This rotation movement around the lamella axis has the function of opening and closeing the lamellas, because they are united by the lamella axis welding. The lever (1) is assembled in the screw. This is welded in the limit between flat washer and locker nut.

The locking system has the function of keeping the lamellas opening in the wanted position; it is made by a toothed plate of rack (3) that allows the fitting of the

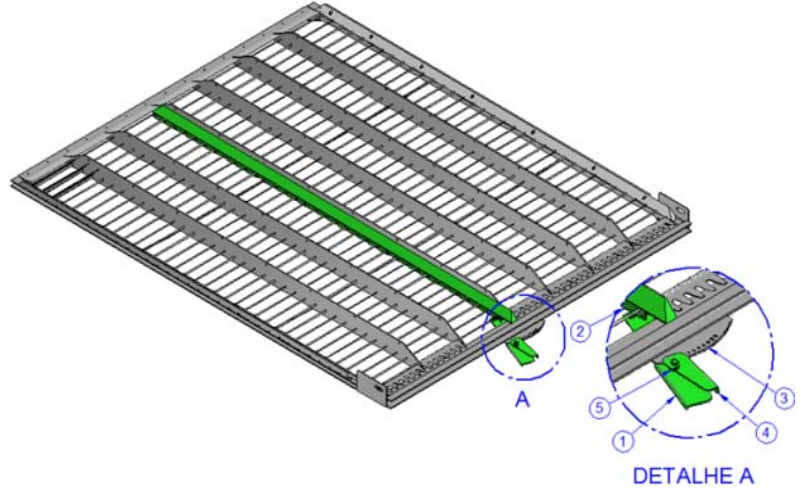

Fig. 28 Chosen conception to the regulating system.

riddle component (4). The riddle (4) is pressed into the rack (3) through a torsion spring (5) and assembled between the lever (1) and the riddle (4), locking the system. The riddle (4) assembling into the lever (1) is made by a screw, a spacer, a flat washer and a locker nut.

In order to make the reading of the regulating lamella opening, the system has a scale with numbered markers in the rack (3), it made the reading according to the lever position (1).

3.1.1 Assembling Project for the New Regulating System

According to the redesign of the regulating system, this subset has all the new components, once they are not going to be adapted or used the solder devices and cutting and bending tools of the current assembling set regulating lever, the same one can be obsolete.

In Fig. 29, the new regulating lever set is made by a lever (1), which is assembled in the solder board set and the solder regulating guide, and it has the function to transmit the linear movement to the solder guide set, moving the same into longitudinal direction of the sieve, from the lever rotating movement (1) around its fixation axis. The subset is made by a riddle (4), that is pressed into the rack trough, the torsion spring(2) that is assembled in the riddle (4), and the lever (1) assuring the system locker. The assembling of these components is made by a spacer (3), a screw (5), a flat washer (6) and a locker nut (7).

The assembling procedure for the new regulating lever set is presented next: 


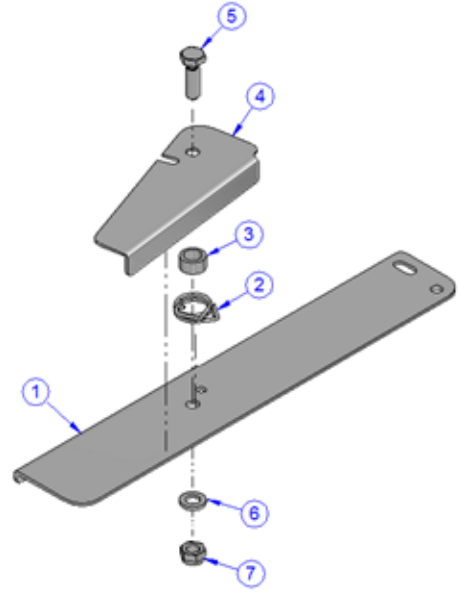

Fig. 29 Exploded view of the new regulating lever system.

- Assemble the riddle (4), a spacer (3) and a torsion spring (2) in the lever (1) by a hexagonal screw M6 $\times$ 20 (5), a flat washer A6 $\times 12.5 \times 1.6$ (6) and a locker nut M6 (7). The screw and nut tightening must allow the riddle to turn freely.

Compare the new assembling procedure with the current one. It is possible to observe that the regulating plate component was eliminated; also the manual riveting procedure of the component is eliminated.

The assembling procedure of the new regulating system remains the same as the current one, the difference of the original project is in the subsets and components which suffer the changing for the new regulation lever set. Due to the regulating system redesign, other sieve set parts have to fit the changes on the position and geometry. The subsets which had improvement impact were the solder board set and the regulating solder guide. These assembling procedure changing in the subsets and components are part of the regulating system.

3.1.2 Welding Project of the New Regulating System

Due to regulating solder set being related to the regulating system, it was necessary to fit the same solder according to the system redesign. The only difference of the regulating older guide of the new system compared to the current one is the screw position. For the new system, it was necessary to move the screw, make it get closer to the regulating guide extremity, being necessary investment to adapt the current welding device according to the new set.

As shown in Fig. 30, this subset is made of a regulating guide (1), when triggered move into the longitudinal direction of the sieve, the lamella axis turn around its axis, consequently, regulating the lamella opening, because the same are united by their welding axis, and a hexagonal screw M6 $\times 12$ (2) welded in the regulating guide (1), which has the function of assemble this set into the subset of assembling the regulating lever.

For this subset, it was kept the same welding procedure of the current system, as observed below:

- Welding with MAG a hexagonal screw M6 × 12 (2) into the regulating guide (1) with device.

The regulating guide (1) did not suffer any change due to the regulating system redesign, this way, it was kept the same component with the manufacturing procedure described previously.

The solder board is the sieve main subset, besides having the structural function, it is assembled all the subsets and sieve components. This subset suffers some changes due to the regulating redesign system, being necessary investment to adapt the current device according to the new solder board.

In the original project, it is welded the regulating coupler in the limit and in this, it welded a screw, which has the function to assemble the regulating lever subset,

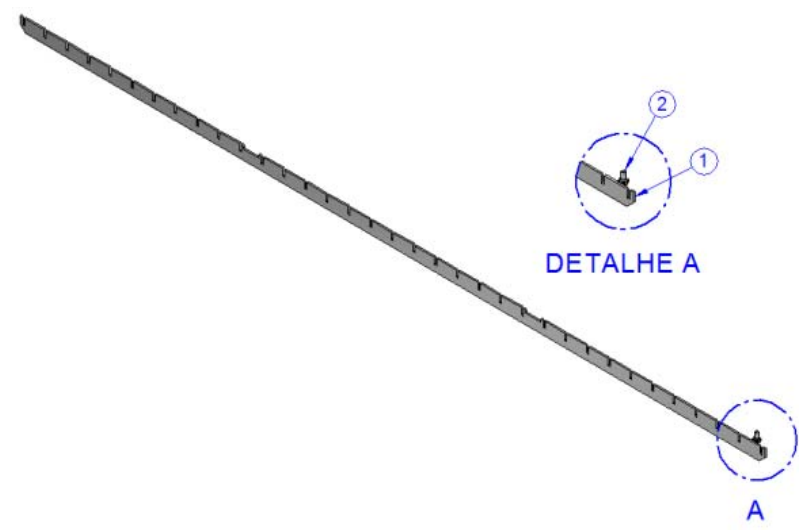

Fig. 30 Isometric view of the regulating solder guide. 
and it also welded the rack set into the traverse,which has the function to lock the system by its toothed profile, keeping the lamella opening in the desired position and doing the regulating reading in the lamella opening, from the number of teeth and the lever position.

In the new system, the regulating coupler was excluded and only the welded screw in the limit was preserved, and the solder rack set, was replaced by the rack component, as shown in Fig. 31.

The welding procedure for the new solder board, as regulating system redesign is described below:

- Weld with MAG a hexagonal srew M6 × 12 (2) with device in the solder board set;

- Weld with MAG a rack (1) with device in the solder board set.

Comparing the new welding procedure with the current one, it is possible to observe that the regulating coupler component was eliminated; consequently, the welding procedure was eliminated.

3.1.3 Project for Manufacturing of the New Regulating System

Fig. 32 shows the new rack which has the function to lock the system and allows the lamella opening regulating reading, by a numbered scale marker; it can make a reading according to the lever position.

The size dimensioning of the rack numbers scale is based on 2.1.1, which described that the words and numbers size is depend on reading distance. According to Table 2, it is specified the height of $4.5 \mathrm{~mm}$ to the distance of $500 \mathrm{~mm}$ to $900 \mathrm{~mm}$, which is the approximately distance to the reading case of lamella opening.

Comparing the new rack with the current one, it is verified that the locker component and the welding procedure was eliminated, and consequently, a welding device is eliminated.

The new rack has the material and the manufacturing procedure below:

- Material thickness 2.00 mm SAE 1008;

- Cut in the laser cut machine as program.

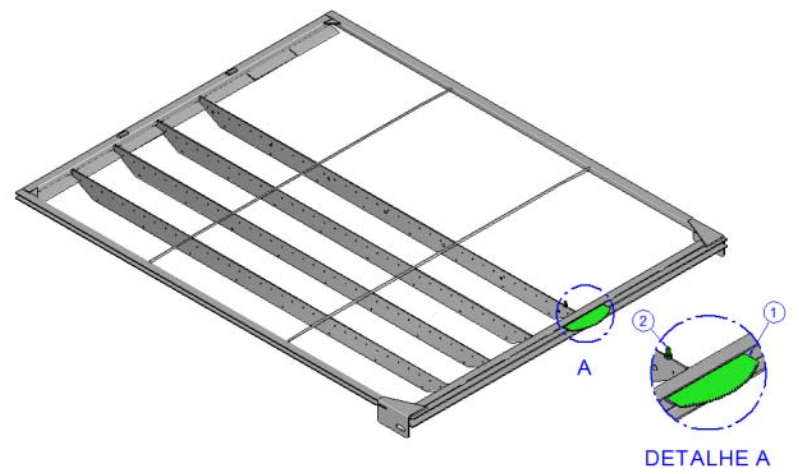

Fig. 31 Lower part of solder board subset with welding detail of regulating system.

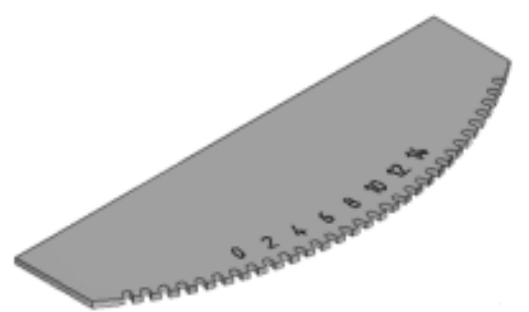

Fig. 32 Isometric view of the rack.

In the rack component, comparing to the current one, it is also verified that the bending operation was eliminated and the thickness was reduced from 2.65 $\mathrm{mm}$ to $2.00 \mathrm{~mm}$, being a component that does not suffer greater requests because of its function. It was kept the material SAE 1008, being easy to obtain and keep in the company stock.

Fig. 33 shows the regulating lever, which is the manual system trigger, with the function to move the regulating solder set into the longitudinal direction.

For the regulating lever dimensioning, it was considered the 2.1.1, Table 1 specifies the measure of $10.6 \mathrm{~cm}$ for the average hand thickness, of $13.4 \mathrm{~cm}$ for the catch perimeter, which is equivalent to a diameter of $4.26 \mathrm{~cm}$. This way, the lever is dimensioned with a length, in the area where the operator handles the lever, of $106 \mathrm{~mm}$ and thickness of $43 \mathrm{~mm}$.

Comparing the new lever to the current one, it is observed the coupler spring component and the welding procedure were eliminated. Consequently, the welding element was eliminated.

For the new regulating lever, following is the material and manufacturing procedure: 


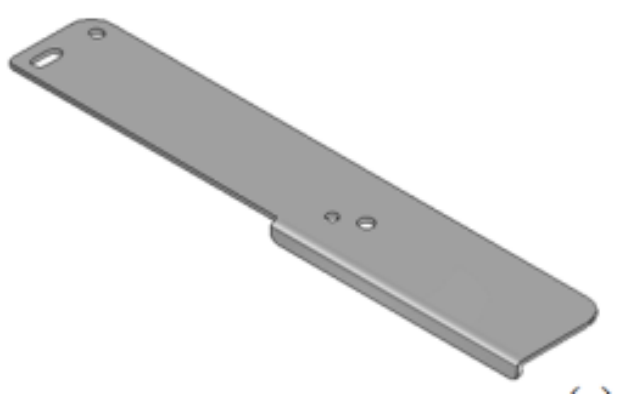

Fig. 33 Isometric view of the regulating lever.

- Material thickness 2.00 mm SAE 1008;

- Cutting blank in the laser cutting machine as program;

- Bending as program.

In the regulating lever component, comparing to the current one, it is also verified that the geometric form changed by the inclusion of bending and dimensions, as anthropometric study, the purposes are improving the handling and reducing the hand tension concentration, reducing this way the injuries and pain during the handling. It is also reduced the thickness from $2.65 \mathrm{~mm}$ to $2.00 \mathrm{~mm}$. The material SAE 1008 was kept for being easy to obtain and keep in the company stock.

Fig. 34 shows the component named riddle, in the original project, which is part of the locking system, it is assembled in the regulating lever, and has the function to assure the desired lever position.

The dimensioning of this component is consequence of the setting developed for the regulating system and locking system working.

Comparing the new riddle with the current one, it is verified the coupler spring and locker components, and the welding procedure of these parts were eliminated. Consequently, the welding device was eliminated.

The new riddle has the material and manufacturing procedure next:

- Material thickness 1.40 mm NBR 5915 EM;

- Cutting the blank in the laser cut machine;

- Bending as program.

It is observed in this component, comparing to the current one, the elimination of two bending included a

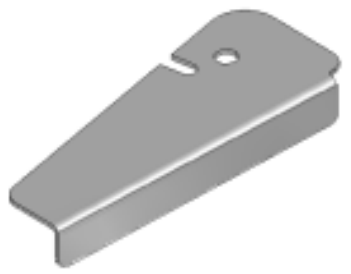

Fig. 34 Isometric view of the riddle.

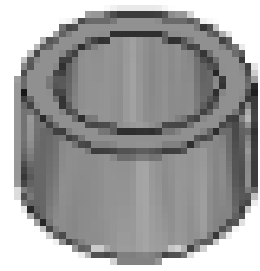

Fig. 35 Isometric view of the spacers.

flap bender is improving the handling and reduce the hand tension concentration. Due to the components function, the material thickness was changed from 2.65 SAE 1008 to 1.40 NBR 5915 EM. The thickness definition is based on the original project, the component locks welded into the riddle solder, it has the main function to lock the system and it has the material thickness 1.50 NBR EM. It was defined by being easy to obtain and stock.

Fig. 35 shows the spacer which is assembled between the regulating lever and the riddle, allowing the assembling of the torsion spring, is a locking system component and has the function to keep the system locked.

This component was dimensioned according to the needed distance between the regulating lever and the riddle and also according to the torsion spring dimensions.

Analyzing the function of this element and the current regulating lever set, it is verified this substituted two flat washers A6 × $12.5 \times 1.6$ which have the spacer function.

The spacer has the following material and manufacturing procedure:

- Material steel round tube $\varnothing 12 \times 1.75$ mm NBR 8437 SAE1, 010/20 s/c;

- Cutting the length in the saw;

- Removing the burrs. 
The other components, as torsion springs, screws, nuts and washers, were not detailed, once they are standard item, they bought as rules and supplies catalogs.

3.1.4 Ergonomic Design of the New Regulating System

Form the ergonomic view, the handling was improved due to the regulating lever geometry and the riddle which have bended flaps. This way, it was increased the handling contact area and consequently, it reduced the hand tension concentration. The regulating lever length and the catch diameter were dimensioned according to the anthropometric measures, assuring a better handling.

In Fig. 36, from the prototype construction, it was verified that the previously anthropometric hand proportion has relation with the geometric dimensions of the new regulating lever, which can be compared to the current regulating system.

Fig. 37 verifies the catch improvement during the lever handling, which can be compared to the current regulating system. The way how the movements are transmitted and the handle style are the same of the current regulating system.

3.1.5 Analysis of Requests and Numbering Simulation of the New Regulating System

After analyzing the new regulating system, it was also conclude that the regulating lever is the main component and suffers the greater requests. In this way, an analysis of the finite elements only for this component will be done, to compare with the numbering simulation of the current system, which will be a dimensioning parameter of the new regulating system.

The charge $\mathrm{F}$ in which the regulating lever is submitted to regulate the lamella opening and fixation points for the finite element simulation is represented in Fig. 38.

In this simulation, considering $20 \mathrm{~kg}$ as applied charge in the regulating lever, the same lever used in the current regulating lever simulation.

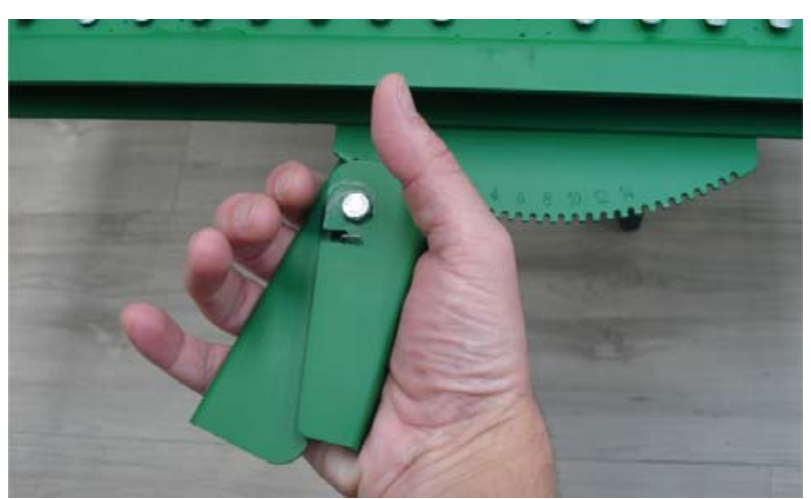

Fig. 36 Handling detail of the regulating lever.

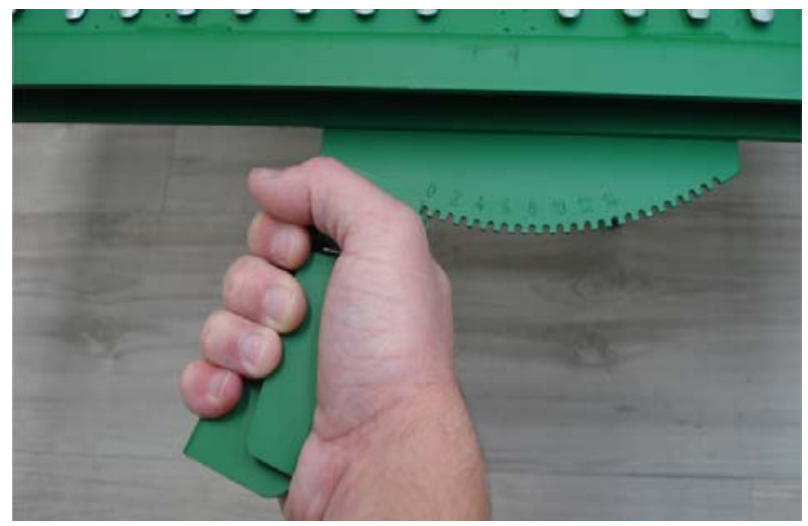

Fig. 37 Catch detail in the regulating lever handling.

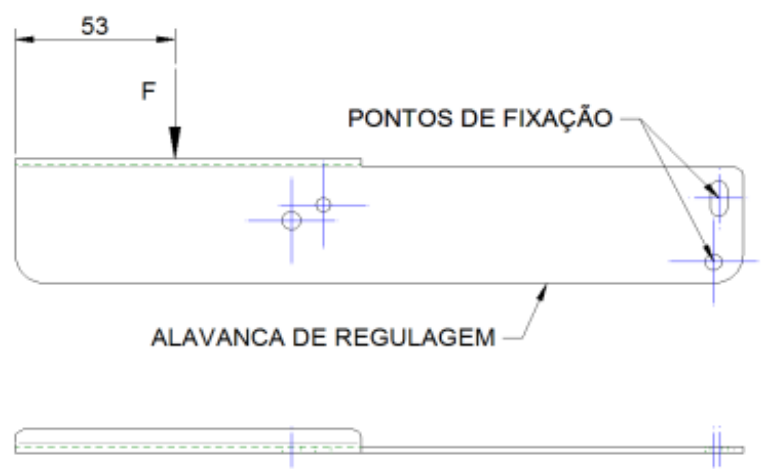

Fig. 38 Charge representation and fixation points for the new regulating lever simulation.

According to the Fig. 39, the maximum tension obtained in the simulation for the load shown in Fig. 38 is about $80 \mathrm{MPa}$, being the tension value a little superior to the found in the current regulating lever, in which the maximum tension found was $60 \mathrm{MPa}$. Fig. 40 presents a maximum deformation of $0.7 \mathrm{~mm}$, a little above of the current which has the deformation of 0.5 $\mathrm{mm}$.

Based on this, the geometry thickness $2.00 \mathrm{~mm}$ used 


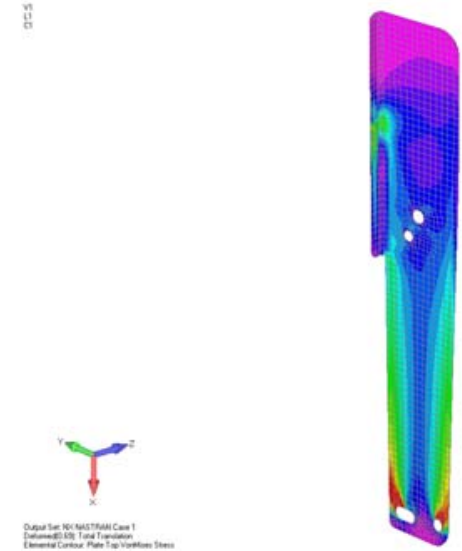

Fig. 39 Tension map for the new regulating system.

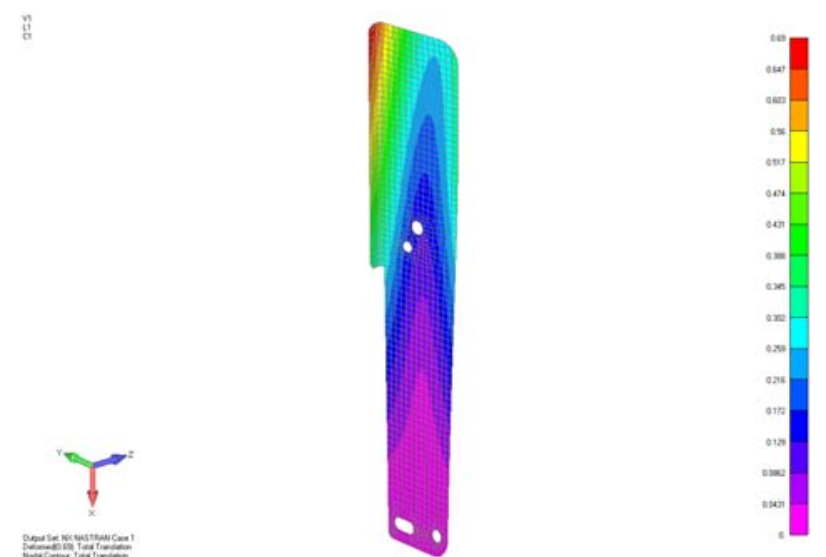

Fig. 40 Deformation map for the new regulating lever.

in the new lever, are safely dimensioned. Even the maximum tension found in the simulation is much lower than the material SAE 1008 flow, for a safety reason, we developed a new regulating lever to have the parameter and the result of the numeric simulation of the current lever.

\section{Conclusions}

Through the regulating sieve system redesign, it was verified from the study and criteria application, rules and project considerations, during the developing, it is possible identify the improvements and develop a new system by a simple project, improving the ergonomic, reducing the cost and keeping the same performance from the original project. Due to simple geometry and specified tolerance for the new system, allowing easy manufacturing and assembling, the manufacturing process from the laser cutting operation machine and bending presses was defined at first. There is also the possibility to manufacture parts from cutting and bending tools, obtaining a lower cost, however with an investment and bigger amortization time.

The new regulating system presented a cost reduction, a reduction in the number of parts and the number of manufacturing and assembling process, it can ease manufacturing and assembling, improve the ergonomic aspect with simple geometric form and proper dimension, ease reading and regulating, ease handling and operation, and keepeg the same performance and endurance from the current regulating system. This way, it can be verified the goals were reached.

\section{References}

[1] Dufour, C. A. 1996. "Studying of the Process and Redesign Tools of Industrial Products, as Competitive Advantage and Constant Improvement Strategy.” master thesis, Federal University of Santa Catarina.

[2] Valdiero, A. C. 1997. Inovation and Project Development of Industrial Products. Ijuí: UNIJUÍ.

[3] Back, N. 1983. Metodoly of Industrial Products Project. Rio de Janeiro: Guanabara Dois.

[4] Hashim, F. M., Juster, N. P., and Pennington, A. G. 1993. "Generating Design Variants Based on Functional Reasoning.” In Proceedings of the International Conference on Engineering Design. ICED '93, 60-7.

[5] Iida, I. 1990. Ergonomic: Project and Production. São Paulo: Edgard Blücher Ltda.

[6] Grandjean, E. 1998. Ergonomic Manual: Adjusting Men's Work. Porto Alegre: Bookman.

[7] Shigley, J. E., Mischke, C. R., and Budynas, R. G. 2005. Mechanical Engineering Project. Porto Alegre: Bookman.

[8] Müller, R. G. 2012. Study of the Rotating Shearing Process. Conclusion Course Work. Panambi: Northwest Regional University of Rio Grande do Sul-UNIJUÍ.

[9] Back, N. 2008. Integrated Product Project: Planning, Conception and Shaping. Barueri: Manole. 